\title{
A espiritualidade como ferramenta no enfrentamento do HIV/AIDS
}

\author{
Spirituality as a tool in the fight against HIV/AIDS
}

\author{
La espiritualidad como herramienta en la lucha contra el VIH/SIDA
}

Lucas Antonio de Oliveira Santos ${ }^{1}$, Viviane Alves da Silva1', Bruna Caroline Ribeiro Beltrão ${ }^{1 *}$, Augusto César Beltrão da Silva ${ }^{1}$, Alba Angélica Nunes Mouta², Francisco Jander de Sousa Nogueira², Nereu Bastos Teixeira Costa ${ }^{1}$, Yuri Dias Macedo Campelo ${ }^{1}$, Vanessa Menezes de Brito Campelo', Renata Paula Lima Beltrão².

\section{RESUMO}

Objetivo: Analisar a espiritualidade como uma ferramenta terapêutica no convívio com o vírus da imunodeficiência adquirida/Síndrome da Imunodeficiência Adquirida (HIV/AIDS), na qualidade de vida e na saúde mental e emocional das pessoas que vivem com HIV/AIDS (PVHA). Métodos: Estudo quanti-qualitativo que utilizou como população de estudo 10 usuários regularmente acompanhados pelo Centro de Orientação e Aconselhamento Sorológico/ Centro de Testagem e Acolhimento (COAS/CTA). Estes pacientes foram submetidos a uma entrevista estruturada que visava entender a relação deles com a religiosidade e com a espiritualidade. Resultados: Foi observado que $100 \%$ dos entrevistados acreditavam em um ser superior, embora $30 \%$ deles não possuíssem nenhuma religião. A espiritualidade pode atuar como um fator negativo ou positivo no enfrentamento da doença, visto que algumas pessoas podem encarar a doença como um castigo divino, enquanto outras veem na religião um amparo para o enfrentamento da sua condição, se sentindo aceitos e amados por um ser superior. Conclusão: Quando a relação com a espiritualidade ocorre de maneira positiva, ela é vista como suporte para a superação da situação crônica de cuidado. Porém, quando a relação é negativa, o paciente tem nesta um fator a mais de culpa e sofrimento.

Palavras-chave: Espiritualidade, HIV, Síndrome de imunodeficiência adquirida, Religião.

\begin{abstract}
Objective: To analyze spirituality as a therapeutic tool in living with the acquired immunodeficiency virus / Acquired Immunodeficiency Syndrome (HIV / AIDS), in the quality of life and in the mental and emotional health of people living with HIV / AIDS (PLWHA). Methods: Quanti-qualitative study that used 10 study users regularly monitored by the Serological Guidance and Counseling Center / Testing and Reception Center (COAS / CTA). These patients were submitted to a structured interview that aimed to understand their relationship with religiosity and spirituality. Results: It was observed that $100 \%$ of respondents believed in a superior being, although $30 \%$ of them did not have any religion. Spirituality can act as a negative or positive factor in coping with the disease, since some people may view the disease as a divine punishment, while others see in religion a support for facing their condition, feeling accepted and loved by a being higher. Conclusion: When the relationship with spirituality occurs in a positive way, it is seen as a support for overcoming the chronic care situation. However, when the relationship is negative, the patient has an additional factor of guilt and suffering.
\end{abstract}

Keywords: Spirituality, HIV, Acquired immunodeficiency syndrome, Religion.

\footnotetext{
${ }^{1}$ Instituto de Ensino Superior do Vale do Parnaíba (IESVAP), Parnaíba - PI.

*E-mail: brunacrbeltrao@gmail.com

²Universidade Federal do Delta do Parnaíba (UFDPar), Parnaíba - PI.
} 


\section{RESUMEN}

Objetivo: Analizar la espiritualidad como herramienta terapéutica para vivir con el virus de inmunodeficiencia adquirida / Síndrome de inmunodeficiencia adquirida (VIH / SIDA), en la calidad de vida y en la salud mental y emocional de las personas que viven con VIH / SIDA (PVVS). Métodos: Estudio cuantitativo que utilizó 10 usuarios del estudio monitoreados regularmente por el Centro de Orientación y Asesoramiento Serológico / Centro de Pruebas y Recepción (COAS / CTA). Estos pacientes fueron sometidos a una entrevista estructurada que tenía como objetivo comprender su relación con la religiosidad y la espiritualidad. Resultados: Se observó que el $100 \%$ de los encuestados creía en un ser superior, aunque el $30 \%$ de ellos no tenía ninguna religión. La espiritualidad puede actuar como un factor negativo o positivo para hacer frente a la enfermedad, ya que algunas personas pueden ver la enfermedad como un castigo divino, mientras que otras ven en la religión un apoyo para enfrentar su condición, sentirse aceptados y amados por un ser mayor. Conclusión: Cuando la relación con la espiritualidad se produce de manera positiva, se ve como un apoyo para superar la situación de atención crónica. Sin embargo, cuando la relación es negativa, el paciente tiene un factor adicional de culpa y sufrimiento.

Palabras-clave: Espiritualidad, VIH, Sindrome de inmunodeficiência adquirida, Religión.

\section{INTRODUÇÃO}

A Síndrome da Imunodeficiência Adquirida (AIDS) é o resultado da infecção, em estágio avançado, pelo vírus da imunodeficiência humana (HIV), que ataca células de fenótipo tipo CD4-+, dentre elas, os linfócitos $\mathrm{T}$, responsáveis por uma das linhas de defesa do organismo humano, aumentando a suscetibilidade do indivíduo às infecções oportunistas. Sua epidemia, desde meados de 1981, mostrou-se como fenômeno global, de rápida progressão, instável e dinâmico, de caráter quase essencialmente comportamental, associado de modo político-religioso à grupos moralmente marginalizados pela sociedade conservadora, heteronormativa e temente a uma força espiritual delineadora de comportamentos aceitáveis (BRITO AM, et al., 2001).

De acordo com o Boletim Epidemiológico de HIV e AIDS divulgado pelo Ministério da Saúde (MS), em novembro de 2019, estima-se que, no Brasil, 866 mil pessoas vivam com o HIV/AIDS (PVHA). Há um consenso de que o enfrentamento da doença se sobreponha às questões físicas diretas da interação agentehospedeiro: a gravidade prognóstica, a ausência de cura a terapia antirretroviral e seus efeitos colaterais e das afecções imunodependentes. Ainda permanecem extensos prejuízos emocionais e psicossociais plantados desde a descoberta viral e de suas formas de transmissão, onde gays, prostitutas e dependentes químicos pareciam ser punidos de modo fatídico por suas inadequações de conduta social (SEIDL EMF, 2010; BRASIL, 2019).

Com a evolução científica, os avanços terapêuticos foram capazes de promover a migração do caráter da AIDS, de moléstia subaguda e mortal para doença crônica controlável. Aguardava-se ansiosamente que os portadores do HIV gozassem do incremento na sobrevida, da melhoria direta na qualidade de vida e inserção social sem restrições. Entretanto, a qualidade de vida das PVHA ainda se mantém tolhida pelas diversas necessidades de rotina impostas pela condição soropositiva, que vão das rotineiras visitas médicas à tomada diária de comprimidos; bem como ainda persiste o preconceito, o medo e a insegurança, determinando sofrimento às PVHA (PINHO CM, 2017).

Esses eventos estressores, frente aos quais, comumente, se acham os indivíduos portadores de HIV/AIDS, aumentam três a quatro vezes o risco de desenvolver depressão e outras psicopatologias, representado numericamente a suscetibilidade das PVHA a padecimentos abióticos (OLIVEIRA ELL, et al., 2009).

As doenças crônicas, em especial o HIV/AIDS é capaz de interferir em toda a dinâmica existencial de um indivíduo, seja no âmbito social, financeiro, físico e/ou cultural devido aos impactos causados no arcabouço psicológico. Nesse contexto, um dos mais notórios aspectos de mudanças visto são as questões religiosas e espirituais que se tornam vertentes de auxílio para tratamentos, corroborando a tese de que religião e ciência 
se complementam. Exemplo disso, é que desde o início da década de 1980 a medicina vem tendo um direcionamento de maior abrangência nas áreas complementares a fisiopatologia, dando ênfase e relevância de fatores sociais e psicossociais (GRECO DC, 2016)

Hipólito RL, et al. (2017); mostra que a espiritualidade tem uma relação íntima com a melhora da qualidade de vida em pacientes com doença crônicas, constituindo um fator importante na percepção como essas pessoas enxergam a qualidade de vida, porém, ainda tem sido negligenciada em grande parte dos estudos com PVHA. Aspectos ligados à religiosidade e a espiritualidade são apontados por diversos autores como possíveis fontes de apoio social no enfrentamento da doença, especialmente em doenças crônicas, como 0 HIV/AIDS (FERREIRA DC, et al., 2016).

A espiritualidade então foi declarada como estratégia terapêutica auxiliar para PVHA e/ou outras moléstias, inclusive pela Organização Mundial de Saúde (OMS); e foi compreendida como busca individual para um sentido último por meio da crença em Deus ou deuses, religiões, correntes filosóficas e até mesmo nas artes. (FARIA JBD, SEIDL EMF, 2006; REGINATO V, 2016).

Infelizmente, na medicina ocidental tradicional, focada na clínica medicamentosa e cirúrgica, a espiritualidade dos pacientes é pouco explorada e possui reduzido espaço no meio acadêmico. No entanto, diversos estudos apontam a espiritualidade como uma ferramenta de melhora da qualidade de vida dos pacientes crônicos, servindo como instrumento de bem estar e de reconstrução para conceitos relevantes no enfrentamento do HIV/AIDS (BELTRÃO RPL, et al., 2020).

\section{MÉTODOS}

Este trabalho busca analisar a espiritualidade como interferência terapêutica no convívio com o HIV/AIDS, na qualidade de vida e na saúde mental e emocional das PVHA. Propõe uma análise quantitativa e qualitativa, em um estudo transversal dos aspectos espirituais dos pacientes previamente diagnosticados e assistidos pelo Centro de Orientação e Apoio Sorológico/Centro de Testagem e Aconselhamento (COAS-CTA) em um município do Piauí. É um braço de uma pesquisa maior, que foi aprovada pelo Comitê de Ética da Universidade Federal do Piauí (UFPI), com o registro de número 2.402.713.

Trata-se de uma pesquisa quantitativa e qualitativa, baseada na análise de discurso e formação gráfica de Corpus e Nuvens. O universo do estudo foram os 378 usuários regularmente acompanhados pelo COAS-CTA de Parnaíba-PI, sabidamente PVHA, excetuando-se os menores de 18 e maiores de 70 anos, bem como os portadores de alguma deficiência neurocognitiva que impossibilitassem a realização da pesquisa. Foram convidados a participar 10 usuários escolhidos aleatoriamente, que responderam um formulário semiestruturado da pesquisa. Essas pessoas foram denominadas numericamente, como paciente 1 até paciente 10.

Os participantes foram instruídos quanto ao intuito, métodos e instrumentos de estudo. Todos os participantes foram informados sobre os possíveis riscos e benefícios dos procedimentos. Em seguida, orientados, caso concordem, a assinar o Termo de Consentimento Livre e Esclarecido (TCLE). Na sequência, foram submetidos a um formulário sócio demográfico e convidados a participar de entrevistas individuais, com conteúdo de áudio a ser gravado, mantendo o caráter anônimo dos participantes na mídia registradora.

O conteúdo sonoro foi utilizado apenas para os fins desta pesquisa, comprometendo-se a pesquisadora com a não divulgação do conteúdo. Quando oportuno, foram utilizadas questões disparadoras previamente desenhadas, no intuito de direcionar a conversa para o esclarecimento dos pontos elencados, sobre a temática da espiritualidade.

Os dados coletados a partir dos formulários foram tabulados e analisados no software estatístico SPSS, em sua versão 21, realizadas análises descritivas a fim de caracterizar a amostra, frequências e porcentagens, ilustrados em gráficos para representar os resultados obtidos a partir dos objetivos propostos. Os bancos textuais foram cuidadosamente lidos e analisados por meio de um software de análises de dados textuais chamado Iramuteq (Interface de $R$ pour analyses Multidimensionnelles de Textes et de Questionnaires) (MARCHAND P, RATINAUD P, 2009), que é hospedado no software $R$ (R Development Core Team, 2011). 
A partir desta ferramenta, dois procedimentos estatísticos foram realizados. O primeiro consiste na análise de Nuvem de palavras que as organiza representativamente de acordo com a frequência em que aparecem. É uma análise lexical mais simples, porém, constitui um recurso gráfico pertinente, na medida em que possibilita identificação direta das palavras-chave de um corpus. Então, executou-se a Análise de similitude. Este procedimento possibilita identificar as co-ocorrências entre as palavras, fornecendo indicações da conexidade entre elas, estimando a estrutura de um corpus (MARCHAND P, RATINAUD P, 2012). Por fim, será realizada a análise discursiva, com finalidade de apresentar fidedignamente as falas dos participantes.

\section{RESULTADOS E DISCUSSÃO}

Dentre os 10 participantes da pesquisa, $80 \%$ eram do gênero masculino e os extremos de idade foram 23 e 44 anos, com uma média de 30 anos. Todos os participantes relataram acreditar em Deus na época anterior ao recebimento do diagnóstico de HIV/AIDS, no entanto, 30\% deles afirmaram não ter ligação com nenhuma religião nem frequentar igreja/culto. A religião aqui foi entendida como uma prática coletiva, de manifestação de atos de culto, ritos e outras formas de expressão, de caráter cultural e social (SILVA JB, SILVA LB, 2014).

Após o resultado do diagnóstico, todos alegaram manter a crença em Deus, no entanto houveram mudanças relativas a adesão à religião, visto que dos três participantes que relataram não ter nenhuma religião, dois deles passaram a frequentar alguma igreja/culto e um dos participantes que afirmava ter religião, relatou abandoná-la após receber o resultado.

Foi observado durante a análise do questionário semi-estruturado que o resultado positivo para teste sorológico do HIV impactou também na frequência com que os indivíduos compareciam à igreja/culto. Dentre os participantes, 4 afirmaram ter aumentado a assiduidade com que iam às atividades religiosas; 5 deles relataram que não houve mudança na regularidade de suas práticas religiosas e 1 participante declarou que, após o recebimento do diagnóstico, deixou de frequentar qualquer atividade relacionada à religião.

Faria JBD e Seild EMF (2006); já apresentavam o padrão negativo da influência da soropositividade na religiosidade do indivíduo, que seria caracterizada pelo descontentamento da percepção religiosa quanto a doença, presença de conflitos interpessoais com membros do grupo religioso, receio da descoberta e da receptividade e de dúvidas sobre os poderes de Deus para interferir na situação estressora.

De acordo com o MS e com a OMS, a espiritualidade é uma das principais vertentes terapêuticas contra o HIV, auxiliando não só na adesão ao tratamento, mas também na luta contra o preconceito e a discriminação (BRASIL, 1998).

Dentre os participantes da pesquisa, todos referiram ter espiritualidade e acreditar em uma força maior, nominada por todos como Deus. $80 \%$ dos entrevistados apontou a espiritualidade como ferramenta positiva no enfrentamento da doença e dos desafios impostos por ela, influenciando diretamente na qualidade de vida e na adesão ao tratamento medicamentoso e não-medicamentoso; afetando o ânimo, a vontade e a determinação dos pacientes com relação aos cuidados contínuos exigidos pela condição soropositiva. A exemplo, podemos elencar a fala de um dos entrevistados:

"Tive como base a oração para me sustentar. Antes não tive muito cuidado comigo e nem com os outros. Hoje valorizo os princípios de uma vida melhor, e também hoje me acho melhor como ser humano do que antes." (Paciente 3)

$\mathrm{Na}$ avaliação da fala, a "oração" é colocada como uma expressão da espiritualidade, ato ligado ao reforço de vínculo com a entidade divina e apoio ao enfrentamento da condição soropositiva. O recondicionamento do autocuidado e do cuidado com o próximo surge como fruto da revisão de valores, imposta pela mudança de comportamento do paciente. Isso reforça que a espiritualidade representaria não apenas um apoio emocional, mas estaria ligada às mudanças comportamentais que favorecem a uma vida mais saudável, como a hesitação de práticas perigosas quanto à infecção e à transmissão do vírus - sexo sem códons ou sem uso da profilaxia pré-exposição e o consumo de álcool e drogas injetáveis (SILVA FS, et al., 2015).

As exigências quanto às mudanças comportamentais podem estar muito mais relacionadas às restrições, preceitos, ideologias e normas religiosas, que propriamente espirituais. Apesar da confusão de nomenclatura, 
religião e espiritualidade são conceitos distintos. A espiritualidade está relacionada a uma expressão do ser humano, individual, caracterizada pela intimidade com algo maior e pode ser definida como um sistema de crenças que transmitem vitalidade e significado a experiências humanas, influenciando na qualidade de vida. A espiritualidade pode estar atrelada ou não com uma religião que, por sua vez, é definida como sistema organizado coletivo, relacionado com o sagrado, que geralmente envolve regras comportamentais rígidas e condutas orientadoras da vida num grupo social, com hierarquia definida (SILVA JB, SILVA LB, 2014; FLETCHER MA, 2015; ZERBETTO SR, et al., 2017).

Em muitos casos, o receio do constrangimento de ser apontado como PVHA pode gerar o abandono ou a mudança das práticas religiosas, mesmo que momentaneamente (SILVA FS, et al, 2015). Como pode ser expressa no depoimento do paciente 10, que optou por parar de frequentar o culto/igreja, e ainda afirmou que nem a espiritualidade e nem a religiosidade interferiram em sua relação com a doença e não fazendo diferença em seu cotidiano. Entretanto, ficou claro como a condição sorológica pode modificar a religiosidade, mesmo que de modo negativo. Este foi um caso de "desconversão" religiosa atribuída a vivência com o HIV. Esse comportamento também se reproduziu de modo temporário, como o narrado pelo paciente 2 e pelo paciente 7:

"Na fase inicial de descoberta sim, passou um tempo para voltar a ter certeza que tenho algo maior por mim" (Paciente 2);

"No momento em que recebi o resultado, me afastei da igreja que frequentava, mas em momento nenhum deixei de acreditar em Deus" (Paciente 7).

Entretanto, houve casos em que a infecção não mudou a religiosidade e nem a espiritualidade do paciente. A exemplo disso está o paciente 6, que afirma ter mantido a crença em Deus, relatando ainda que o vírus não interfere em sua fé.

Em contraponto ao exposto, a espiritualidade pode servir de "tábua de salvação" para as pessoas que enfrentam situações ameaçadoras, como a imposta pelo HIV. A necessidade intrínseca ao ser humano de proteção em situações de fragilidade e a necessidade de ter consigo a certeza de algo maior, é capaz de gerar e reforçar crenças (FLETCHER MA, 2015).

Em nossa pesquisa, foram identificados casos de conversão espiritual e religiosa após o diagnóstico da infecção pelo HIV. O paciente 8 afirma que antes da infecção não possuía vida religiosa e nem frequentava nenhuma igreja/culto e depois da infecção passou a frequentar semanalmente. O paciente de número 5 se referiu a AIDS como um fator de provação de sua fé e que lhe fez enxergar a força do Senhor.

No que tange ao preconceito e a discriminação sofridos pelas PVHA, a religiosidade e a espiritualidade não foram apontadas como ferramentas eficaz de enfrentamento durante a pesquisa. Do contrário, foi relatada a estigmatização, o receio e o constrangimento frente a condição soropositiva por parte dos pacientes quanto aos outros frequentadores de locais de cultos de fé, levando pacientes ao estado de alerta constante. Porém, a espiritualidade foi confirmada como instrumento importante para a aceitação individual da situação de portador do vírus, bem como das rotinas exigidas às PVHA, como exemplos destacam-se a fala do paciente 8 e do paciente 1 :

"Depois do contato maior com a espiritualidade, aceitei melhor o fato de conviver com o vírus" (Paciente 8);

"Deus continua me dando serenidade e tranquilidade nos momentos que estou ingerindo a medicação" (Paciente 1).

Embora a infecção pelo HIV não possua uma cura na atualidade, $40 \%$ dos entrevistados afirmaram que possuem em sua espiritualidade a esperança de cura, destacando-se o paciente 2 que afirmar ter a certeza da cura futura. Dentro dos $60 \%$ que responderam "não", reproduz-se a fala do paciente 4, que afirma saber que não há cura, mas que possui na fé uma esperança de melhorar sua qualidade de vida. Dentro da idéia punitiva defendida por Susan Sontag, onde a doença pode ser interpretada como um castigo, o paciente 3 afirma ou ainda na fala do paciente 6 (SONTAG S, 2007): 
"Desde 2015 quando recebi o diagnóstico nunca pedi a cura. Pois antes não tive muito cuidado comigo e nem com os outros. Acredito que ser soropositivo é consequência de um estilo de vida imprudente anterior" (Paciente 3).

"Minhas ações me fizeram chegar a essa condição" (Paciente 6).

Mesmo que para alguns indivíduos o diagnóstico da AIDS possa estar associado a uma ideia de castigo divino, muitos pacientes afirmam que a espiritualidade é uma forma de se sentir aceitos e amados por um ser superior (BELTRÃO RPL, et al., 2020).

Lyon ME (2016) e Lucchetti G (2010) colocam que a qualidade de vida, o bem estar e a espiritualidade estão em conjunto em diversos cenários, ressaltando que a fé e a espiritualidade auxiliam na manutenção da saúde mental e no processo de saúde-doença (FERREIRA DC, et al., 2016).

A espiritualidade seria capaz de gerar efeitos clínicos positivos dentro da terapêutica, refletidos na menor prevalência de depressão pós tratamento, ansiedade, hipertensão arterial sistêmica e taxa de suicídio. Por influência comportamental, a espiritualidade e a religiosidade implicariam na maior adesão à práticas saudáveis e a terapêutica medicamentosa, determinando redução da carga viral e o aumento do número de linfócitos T CD4, bem como diminuição da proteína reativa $C$ (PCR) e das interleucinas, impactando na menor mortalidade dos pacientes (FLETCHER MA, 2015).

Mesmo a espiritualidade sendo um campo rico à terapêutica de pacientes, não foi identificado durante a pesquisa nenhum paciente que afirmasse ter conhecimento de práticas que estimulassem o desenvolvimento e cuidado espiritual voltados às PVHA.

$\mathrm{Na}$ análise gráfica de nuvens, observa-se que os dois elementos mais frequentes dentro dos relatos colhidos são o substantivo Deus e o verbo acreditar, seguidos do substantivo fé, pontos primordiais dentro dos relatos e que norteiam as respostas aos assuntos abordados (Figura 1). Curiosamente, em um país de maioria Cristã (86,7\%), termos como "Cristo", "Maria", "Jesus" e "Espírito Santo" não surgem nos discursos colhidos (IBGE, 2010). O termo "vírus" é um pilar importante da análise dos discursos e se repete na fala de todos os pacientes. "Cura" e "condição" (termo muitas vezes utilizado para substituir ou acompanhar "soropositivo" "portador do HIV" e "HIV reagente") são retóricos nas falas.

Figura 1 - Nuvem de palavras do Corpus. Parnaíba-PI; 2020.

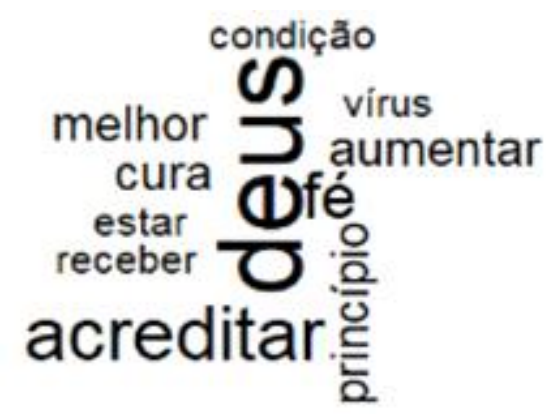

Fonte: Santos LAO, et al., 2020.

O gráfico de similitude avalia a conectividade e a relação dos termos dentro do corpus textual, representando-os através de um grafo composto por regiões focais (ilhas), que possibilitam a análise e interpretação da correlação dos elementos analisados.

Analisando o gráfico de similitude resultante da análise dos relatos, observa-se o surgimento de 3 regiões focais, na qual o termo mais central dentro da ilustração é o verbo acreditar, que se sobrepõe aos demais elementos da "ilha" em verde. O elemento acreditar conecta-se tanto à fé quanto à cura, cura esta que se mostrou dentro da pesquisa um divisor de crenças dentre os entrevistados. A fé é o elemento que conecta os termos da ilha vermelha ao restante do gráfico. A ilha vermelha apresenta como termo central o substantivo deus, relacionando-se ao vírus e ao elemento "condição" (que faz referência a soropositividade) (Figura 2). 
Figura 2 - Gráfico de Similitude. Parnaíba-PI; 2020.

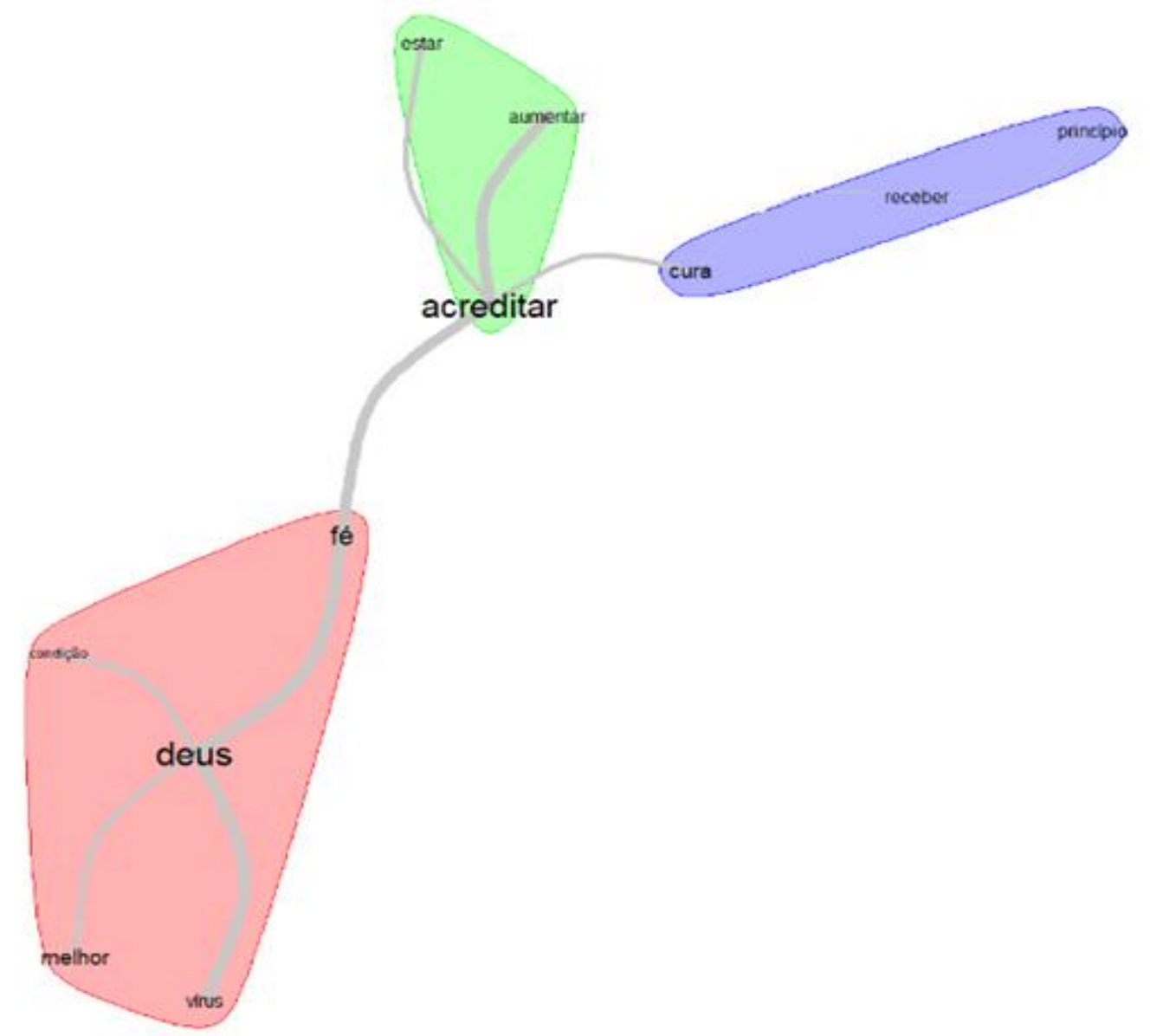

Fonte: Santos LAO, et al., 2020.

\section{CONCLUSÃO}

Foi observado que a espiritualidade tem influência positiva no tratamento e na vivência com o vírus, afetando diretamente o comportamento do paciente. Tal influência pode se dar tanto de maneira positiva, quanto negativa. Quando a relação se dá de maneira positiva, o paciente tem na espiritualidade suporte para superação da situação crônica de cuidado, efeitos adversos da medicação e estigmas sociais. Possuindo no fator espiritual uma ferramenta de conforto e bem estar que the impulsiona a comportamentos proativos com relação ao tratamento e a continuidade de seus planos de vida. Porém, quando a espiritualidade possui relação negativa, e o paciente tem nesta um fator a mais de culpa e sofrimento, esta serve como uma razão a mais para a desestabilização emocional e psicológica, instigando a visão fatalista da condição soropositiva, diminuindo adesão ao tratamento e estimulando o isolamento social.

\section{REFERÊNCIAS}

1. BELTRÃO RPL, et al. Saúde e qualidade de vida das pessoas vivendo com HIV/aids: uma revisão narrativa dos últimos 15 anos. 2020; 40: 1-8.

2. BECERRA-MELO S. La espiritualidad en pacientes que viven con VIH. Cuestiones Teológicas, 2018; 45(103): 149175.

3. BOFF L. Espiritualidade: um caminho de transformação. Rio de Janeiro: Sextante. 2006.

4. BRASIL. Constituição (1998). c Brasília: Senado Federal: Centro Gráfico, 1988.

5. BRASIL. Instituto Brasileiro de Geografia e Estatística. Censo Demográfico, Características gerais da população, religião e pessoas com deficiência, 2015.

6. BRASIL. Ministério da Saúde. Secretaria de Vigilância em Saúde. Boletim epidemiológico. HIV/AIDS 2019. 2019; número especial.

7. BRITO AM, et al. AIDS e infecção pelo HIV no Brasil: uma epidemia multifacetada. Sociedade Brasileira de Medicina Tropical, Uberaba, v. 34, n. 2, p. 207-217, 2001. 
8. ESPÍRITO-SANTO CCD, et al. A espiritualidade de pessoas com HIV/aids: um estudo de representações sociais. Revista de Enfermagem Referência, 2013; (10): 15-24.

9. FARIA JBD, SEIDL EMF. Religiosidade, enfrentamento e bem-estar subjetivo em pessoas vivendo com HIV/AIDS. Psicologia em estudo, 2006; 11(1): 155-164.

10. FERREIRA DC. The influence of religiousness on living with HIV. Interface - Comunic., Saude, Educ., 2012; 16( 41): 383-393.

11. FLETCHER MA, et al. Spiritual coping predicts CD4-cell preservation and undetectable viral load over four years. 2015.

12. GALLO LC, et al. Resiliency in the face of disadvantage: do Hispanic cultural characteristics protect health outcomes?. Journal of personality, 2009; 77(6): 1707-1746.

13. GRECO DB. Trinta anos de enfrentamento à epidemia da Aids no Brasil, 1985-2015. Ciência \& Saúde Coletiva, 2016; 21: 1553-1564.

14. HIPOLITO RL, et al. Quality of life of people living with HIV/AIDS: temporal, socio-demographic and perceived health relationship. Rev. Latino-Am. Enfermagem, 2017; 25.

15. LUCCHETTI G, et al. Espiritualidade na prática clínica: o que o clínico deve saber. Rev Bras Clin Med, 2010; 8(2): $154-8,20$

16. LYON ME, et al. The role of religiousness/spirituality in health-related quality of life among adolescents with HIV: a latent profile analysis. Journal of religion and health, 2016; 55(5): 1688-1699.

17. MARCHAND, P, RATINAUD, P. L'analyse de similitude appliqueé aux corpus textueles: les primaires socialistes pour l'election présiden- 518 Camargo, B. V., Justo, A. M. tielle française. In Actes des 11 eme Journées internationales d'Analyse statistique des Données Textuelles. JADT 2012 (pp. 687-699).

18. OLIVEIRA ELL, et al. Depressão em pacientes com HIV/AIDS. 2009. Disponível em: <http://files.bvs.br/upload/S/0101 5907/2009/v23n3/a1965.pdf>, acesso em: 05 de julho de 2020.

19. PINHO CM, et al. Religious and spiritual coping in people living with HIV/Aids. Revista brasileira de enfermagem, 2017; 70(2): 392-399.

20. REGINATO V, et al. Espiritualidade e saúde: uma experiência na graduação em medicina e enfermagem. Trabalho, Educação e Saúde, 2016; 14(1), 237-255.

21. ROCHA SMM, ALMEIDA MD. O processo de trabalho da enfermagem em saúde coletiva e a interdisciplinaridade. Rev Latino-am Enfermagem, 2000; 8(6): 96-101.

22. SEIDL EMF, et al. Opiniões de jovens universitários sobre pessoas com HIV/AIDS: um estudo exploratório sobre preconceito. Psico-USF, 2010; 15(1): 103-112.

23. SILVA FS, et al. Preditores associados á qualidade de vida em pessoas vivendo com HIV/AIDS: revisão integrativa. Rev. Pre. Infec e Saúde, Santa Cruz do Sul, 2015; 1(2): 53-63.

24. SILVA JB, SILVA LB. Relação entre religião, espiritualidade e sentido da vida. Rev. Logos \& Existência, 2014; 3(2): 203-215.

25. SONTAG S. Doença como metáforas/ AIDS e suas metáforas. Ed. Companhia de bolso.2007

26. ZERBETTO SR, et al. Religiosidade e espiritualidade: mecanismos de influência positiva sobre a vida e tratamento do alcoolista. Esc. Anna Nery, Rio de Janeiro, 2017; 21(1). 